\title{
Hybrid Design Optimization of High Voltage Pulse Transformers for Klystron Modulators
}

Sylvain Candolfi ${ }^{1}$, Member, IEEE, Philippe Viarouge ${ }^{1}$, Davide Aguglia ${ }^{2}$, Member, IEEE, Jérôme Cros ${ }^{1}$

${ }^{1}$ LEEPCI Lab, Québec, Canada, ${ }^{2}$ CERN, Geneva, Switzerland

Keywords: Pulse transformer, optimization

\begin{abstract}
This paper presents a hybrid optimization methodology for the design of high voltage pulse transformers used in klystron modulators. The optimization process is using simplified 2D FEA design models of the 3D transformer structure. Each intermediate optimal solution is evaluated by 3D FEA and correction coefficients of the 2D FEA models are derived. A new optimization process using 2D FEA models is then performed. The convergence of this hybrid optimal design methodology is obtained with a limited number of time consuming 3D FEA simulations. The method is applied to the optimal design of a monolithic high voltage pulse transformer for the CLIC klystron modulator.
\end{abstract}

Presented at: IEEE IPMHVC, 1-5 June 2014, Santa Fe, US

Geneva, Switzerland

January,2015 


\title{
Hybrid Design Optimization of High Voltage Pulse Transformers for Klystron Modulators
}

\author{
Sylvain Candolfi ${ }^{1}$,Member, IEEE, Philippe Viarouge ${ }^{1}$, \\ Davide Aguglia ${ }^{2}$, Member, IEEE, Jérôme Cros ${ }^{1}$ \\ ${ }^{1}$ LEEPCI Lab., Electrical and Computer Eng. Dept., Laval University, G1V 0A6 Quebec (QC), Canada \\ Emails: sylvain.candolfi.1@ulaval.ca, philippe.viarouge@gel.ulaval.ca,jerome.cros@gel.ulaval.ca \\ ${ }^{2}$ CERN - European Organization for Nuclear Research, Technology Dept., Electric Power Converter Group \\ CH-1211 Geneva 23, Switzerland Email: davide.aguglia@cern.ch
}

\begin{abstract}
This paper presents a hybrid optimization methodology for the design of high voltage pulse transformers used in klystron modulators. The optimization process is using simplified 2D FEA design models of the 3D transformer structure. Each intermediate optimal solution is evaluated by 3D FEA and correction coefficients of the 2D FEA models are derived. A new optimization process using 2D FEA models is then performed. The convergence of this hybrid optimal design methodology is obtained with a limited number of time consuming 3D FEA simulations. The method is applied to the optimal design of a monolithic high voltage pulse transformer for the CLIC klystron modulator.

Index Terms — Pulse transformer, optimization
\end{abstract}

\section{INTRODUCTION}

A monolithic pulse transformer based topology is presently under study at CERN for the future CLIC solid state klystron modulators [1]. The tight pulse specifications defined in Figure 1 and listed in Table 1 require a high efficient control of the pulse transformer performances during the design process.

The transformer design methodology needs optimization techniques to maximize performance objectives in terms of weight and volume while respecting the constraints. Such a design approach needs magnetic and electrical dimensioning models to derive the transformer equivalent electrical circuit parameters with adequate sensitivity to the design parameters variations and sufficient accuracy in order to guarantee an efficient convergence of the optimization process.

It has been demonstrated in [1] that the electrical equivalent circuit parameters used to compute the objective and constraints functions can be directly derived with better accuracy from a 2D FEA dimensioning model instead of using a simplified analytical dimensioning model.

But the validation of the final optimal solution by 3D FEA simulation of the real transformer structure obtained with the 2D FEA methodology presented in [1] often shows that some specification constraints are not precisely verified. This limitation is mainly related to the $2 \mathrm{D}$ approximation of the $3 \mathrm{D}$ transformer structure.

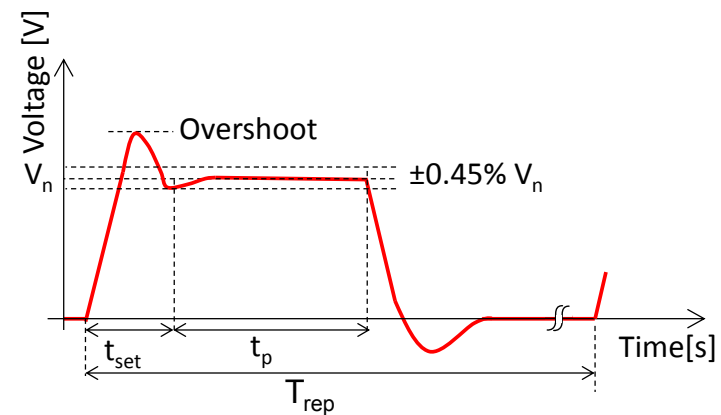

Figure 1: Definition of the specified pulse parameters

Table 1: Specifications of CLIC monolithic pulse transformer

\begin{tabular}{|l|c|c|}
\hline $\begin{array}{l}\text { Transformer and voltage pulse } \\
\text { specifications }\end{array}$ & Value & Unit \\
\hline Peak output power $\mathrm{P}_{\mathrm{p}}$ & 29 & $\mathrm{MW}$ \\
\hline Primary nominal voltage $\mathrm{V}_{1 \mathrm{n}}$ & 15 & $\mathrm{kV}$ \\
\hline Secondary nominal voltage $\mathrm{V}_{2 \mathrm{n}}$ & 180 & $\mathrm{kV}$ \\
\hline Pulse length $\mathrm{t}_{\mathrm{p}}$ & 140 & $\mu \mathrm{s}$ \\
\hline Settling time $\mathrm{t}_{\mathrm{set}}$ & $<8$ & $\mu \mathrm{s}$ \\
\hline Voltage pulse overshoot & $<1 \%$ & - \\
\hline Pulse repetition rate & 50 & $\mathrm{~Hz}$ \\
\hline Transformer Material specifications \\
\hline Insulating material breakdown field $\mathrm{E}_{\max }$ & 10 & $\mathrm{MV} / \mathrm{m}$ \\
\hline $\begin{array}{l}\text { Relative permittivity of insulating } \\
\text { material }\end{array}$ & 3 & - \\
\hline $\begin{array}{l}\text { Relative permeability of core magnetic } \\
\text { material }\end{array}$ & 4000 & - \\
\hline $\begin{array}{l}\text { Saturation flux density of core magnetic } \\
\text { material } \mathrm{B}_{\text {max }}\end{array}$ & 1.15 & $\mathrm{~T}$ \\
\hline Constraints on Transformer Performance and Size \\
\hline Copper losses & $<3 \%$ of $\mathrm{P}_{\mathrm{p}}$ & - \\
\hline Max. overall dimensions & $1 \times 0.5 \times 1.2$ & $\mathrm{~m}$ \\
\hline
\end{tabular}

On the other hand, heavy time consuming 3D FEA simulations are usually not applicable during the iterative optimization process in the case of $3 \mathrm{D}$ devices like the monolithic transformer structure used in modulators. In this paper, a new hybrid optimization methodology is proposed to 
solve this problem: the optimization process is always using simplified 2D FEA design models of the 3D transformer structure but each intermediate optimal solution is evaluated by $3 \mathrm{D}$ FEA simulation. Correction coefficients are derived and another optimization process using corrected 2D FEA models is performed. With this method, the convergence of the hybrid optimal design process is obtained with a limited number of time consuming 3D FEA simulations.

\section{PULSE TRANSFORMER DESIGN OPTIMIZATION}

\subsection{DESIGN VARIABLES}

Because the magnetic and insulating material characteristics, the voltage ratio and the pulse parameters are imposed by the specifications, the state variables of the transformer design optimization problem can be reduced to the core width $\mathrm{e}_{\mathrm{c}}$, the primary winding turn number $\mathrm{n}_{1}$ and the coil height $b_{b}$ (Fig.2). The maximum current density in the windings is fixed by the thermal and efficiency constraints. The core axial length $l$ is then imposed by the fixed material and pulse parameters according to:

$$
l=\frac{V_{1 \text { max }} t_{\text {pulse }}}{n_{1} 2 B_{\max } e_{c}}
$$

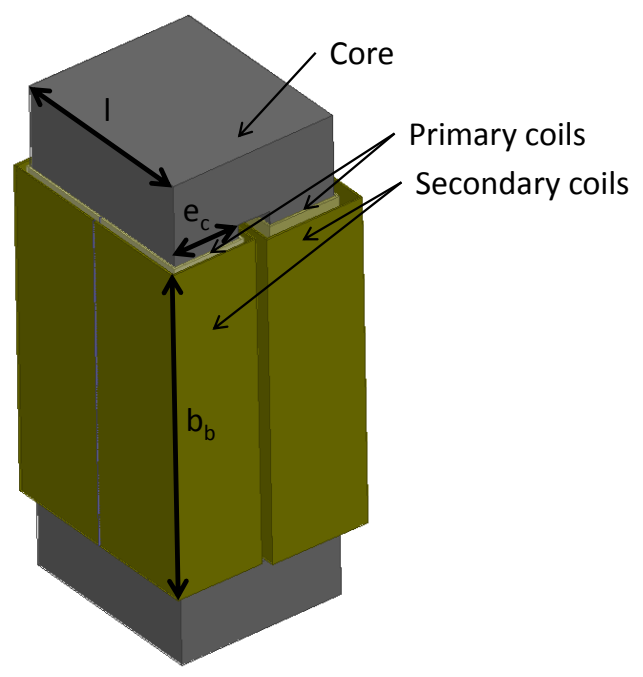

Figure 2: 3D pulse transformer structure

\subsection{ELECTRICAL EQUIVALENT CIRCUIT IDENTIFICATION}

The equivalent electrical circuit defined in IEEE standard (Fig.3) is used to compute the output voltage pulse imposed to the klystron. A specific klystron parameter $a$ defines its nonlinear voltage-current characteristic $U_{k}\left(i_{k}\right)$ according to:

$$
U_{k}=a \cdot i_{k}^{\left(\frac{2}{3}\right)}
$$

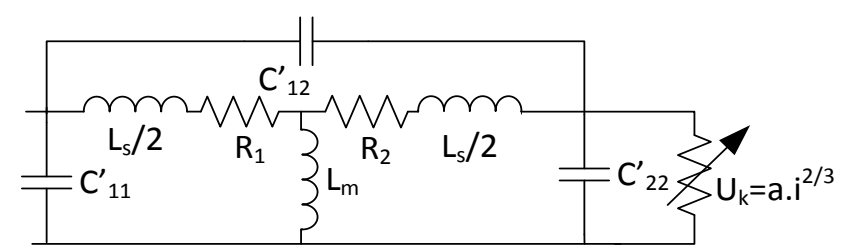

Figure 3: Equivalent circuit of the pulse transformer with its klystron load.

The parameters of the equivalent circuit are directly identified by 2D FEA identification tests based on magnetostatic and electrostatic field computations according to the procedure already detailed by the authors in [1]. Three electrostatic identification tests are required for the determination of the capacitances: test 1 with primary supplied at rated voltage $\mathrm{V}_{1 \mathrm{n}}$, and secondary short circuited \& grounded, test 2 with secondary supplied at rated voltage $V_{2 n}$ and primary short circuited \& grounded, test 3 with primary supplied at $\mathrm{V}_{1 \mathrm{n}}$, and secondary supplied at $\mathrm{V}_{2 \mathrm{n}}$. The capacitances are computed from the three total electrical energy values derived from the electrostatic FEA simulations. Two magnetostatic identification tests are required for the determination of the inductances: test 1 at no-load operation with opened secondary, test 2 under short-circuit operation at rated current. The inductances are computed from the total magnetic energy value derived from each magnetostatic FEA simulation. The symbols and definitions of these energy values are listed in Table 2 .

Table 2. Nomenclature of the energy symbols of equivalent circuit FEA identification tests: 2D model, 2D corrected with $\mathrm{C}_{\mathrm{g}}$, and 3D

\begin{tabular}{|l|c|c|c|}
\hline $\begin{array}{c}\text { FEA Identification } \\
\text { Tests }\end{array}$ & $\begin{array}{c}\text { 2D model } \\
\text { Computed } \\
\text { on length } l\end{array}$ & $\begin{array}{c}\text { 2D model } \\
\text { Corrected } \\
\text { with } \mathrm{C}_{\mathrm{g}}\end{array}$ & $\begin{array}{c}\text { 3D FEA } \\
\text { model }\end{array}$ \\
\hline Electrostatic test 1 & $\mathrm{Wel} 1_{2 \mathrm{D}}$ & $\mathrm{Wel} 1_{2 \mathrm{Dcg}}$ & $\mathrm{Wel} 1_{3 \mathrm{D}}$ \\
\hline Electrostatic test 2 & $\mathrm{Wel} 2_{2 \mathrm{D}}$ & $\mathrm{Wel} 2_{2 \mathrm{Dcg}}$ & $\mathrm{Wel} 2_{3 \mathrm{D}}$ \\
\hline Electrostatic test 3 & $\mathrm{Wel} 3_{2 \mathrm{D}}$ & $\mathrm{Wel} 3_{2 \mathrm{Dcg}}$ & $\mathrm{Wel} 3_{3 \mathrm{D}}$ \\
\hline Magnetostatic test 1 & $\mathrm{Wmag} 1_{2 \mathrm{D}}$ & $\mathrm{Wmag} 1_{2 \mathrm{Dcg}}$ & $\mathrm{Wmag} 1_{3 \mathrm{D}}$ \\
\hline Magnetostatic test 2 & $\mathrm{Wmag} 2_{2 \mathrm{D}}$ & $\mathrm{Wmag} 2_{2 \mathrm{Dcg}}$ & $\mathrm{Wmag} 2_{3 \mathrm{D}}$ \\
\hline
\end{tabular}

According to the two-dimensional finite element modelling assumption, the energy of each 2D FEA test can be only computed on a fixed axial length of the transformer structure in the third dimension. In order to take into account the transformer end-winding region, the energy values are first computed from the 2D FEA solver for an axial length equal to $l$ and then corrected by a geometrical factor $\mathrm{C}_{\mathrm{g}}$. With such an approach, each energy value is not measured on the length of the transformer but on a virtual length that includes the length and the core width $\mathrm{e}_{\mathrm{c}}$ :

$$
C_{g}=1+\frac{e_{c}}{l}
$$

According to the symbols of Table 2, the corrected energy values used to identify the equivalent circuit parameters are:

$$
\begin{gathered}
\text { Wmagi }_{2 D c g}=\text { Wmagi }_{2 D} \times C_{g}, \quad \boldsymbol{i}=2 \\
\text { Weli }_{2 D c g}=W e l \boldsymbol{i}_{2 D} \times C_{g}, \quad \boldsymbol{i}=1,2,3
\end{gathered}
$$




\subsection{OPTIMIZATION METHODOLOGY}

An efficient Generalized Reduced Gradient (GRG2) algorithm is used to perform the transformer design optimization. The objective function to minimize is the transformer volume and the non-linear constraints functions are built from the transformer and voltage pulse specifications listed in Table 1. For each iteration of the optimization procedure, the objective and constraint functions are derived from the three state variables $e_{c}, n_{1}$ and $b_{b}$ by the 2D FEA identification procedures, followed by the simulation of the electrical equivalent circuit of Fig.3. Such a design approach has been successfully applied by the authors in [1], with the limits of the two-dimensional finite element modelling assumption that is using a geometrical correction factor $\mathrm{C}_{\mathrm{g}}$. It is now interesting to evaluate the sensitivity of the optimal design to the limitation of the $2 \mathrm{D}$ approximation by $3 \mathrm{D}$ FEA simulation.

\section{COMPARISON OF 2D AND 3D FEA MODELLING}

To investigate the influence of the two-dimensional finite element modelling assumption on the transformer characteristics, several 3D FEA simulations of the five identification tests have been performed for a transformer with a fixed cross section and a variable axial core length $l$ in the third dimension. For each identification test, the three different estimations of the total electrical (or magnetic energy) are plotted in Fig. 4 according to the terminology of the energy symbols listed in Table 2 . When the core length $l$ goes to infinity, the energy values computed by $2 \mathrm{D}$ and $3 \mathrm{D}$ FEA converge because the contribution of the transformer endwinding region is becoming negligible. One can notice from the five energy-core length characteristics that the ratio between the energy values obtained by 2D and 3D FEA are not identical for each identification test. Fig. 5 presents the electrical field distribution in a horizontal half transformer cross section. One can verify that the average length of the inter-winding space where the most important amount of electrical energy is stored is different from one test to the other.

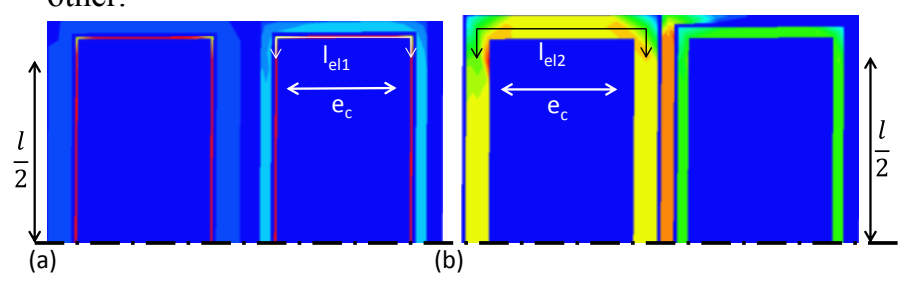

Figure 5: Electrical field distribution in a horizontal half cross section of the transformer, (a) Electrostatic test 1, (b) Electrostatic test 2

Moreover, in the case of the short-circuit test related to the identification of the total transformer leakage inductance, the energy differences are higher even with use of the basic geometrical correction factor $\mathrm{C}_{\mathrm{g}}$. One can conclude from this comparative analysis that different correction factors must be adopted to compute the stored energy in each identification test. The correction mechanism of the hybrid optimization methodology proposed in the next paragraph is taking this conclusion into account.

\section{HYBRID DESIGN OPTIMIZATION METHODOLOGY}

The basic optimization methodology using 2D FEA identification procedures with the geometrical correction factor $\mathrm{C}_{\mathrm{g}}$ described in paragraph 2.3 can be associated to an error compensation mechanism illustrated by the flowchart of Fig.6. For each intermediate optimal design solution, one compares the five energy values given by the 2D FEA to those obtained by a 3D FEA simulation and corrected by $\mathrm{C}_{\mathrm{g}}$. If there is a difference between these two sets of parameters, this solution is not acceptable. One must apply five specific correction factors to the 2D FEA results to improve its accuracy.
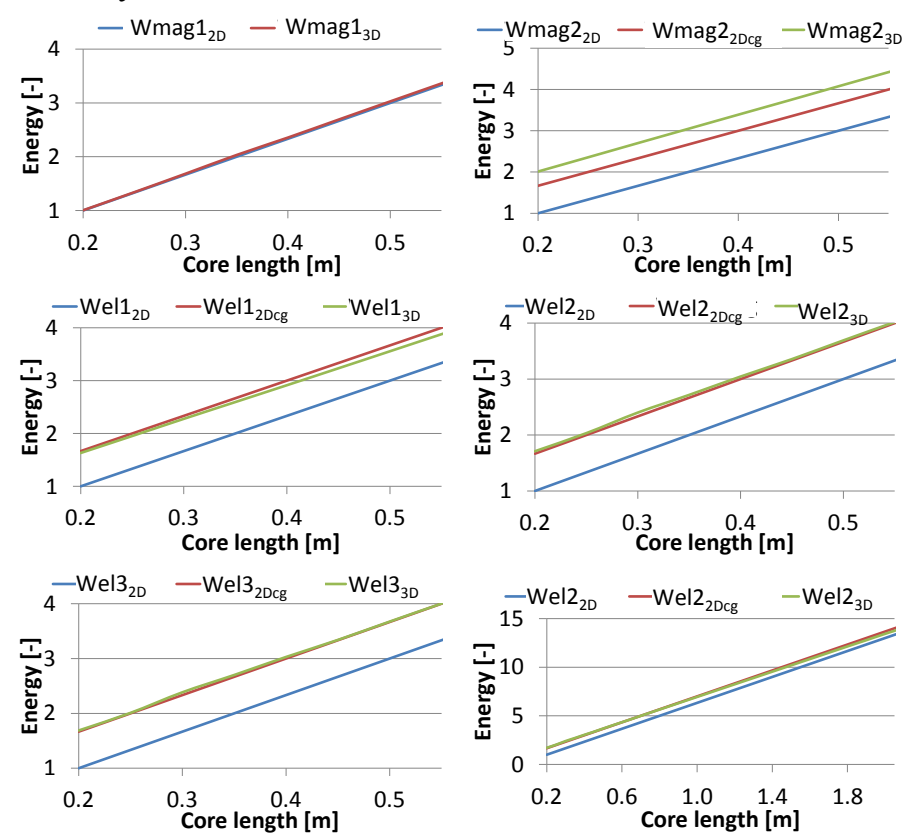

Figure 4: Energy-core length characteristics derived from 2D FEA, 2D FEA with geometrical correction factor $\mathrm{C}_{\mathrm{g}}$ and $3 \mathrm{D}$ FEA for the 5 identification tests

According to the terminology of the energy symbols listed in Table 2, these correction factors are computed from:

$$
\begin{gathered}
\text { Cmagi }=\frac{\text { Wmagi }_{3 \mathrm{D}}}{\text { Wmagi }_{2 \mathrm{Dcg}}}, \quad \mathbf{i}=1,2 \\
\text { Celi }=\frac{\text { Weli }_{3 \mathrm{D}}}{\text { Weli }_{2 \mathrm{Dcg}}}, \quad \mathbf{i}=1,2,3
\end{gathered}
$$

The corrected energy values used to compute the equivalent circuit parameters are then:

$$
\begin{gathered}
\text { Cmagi } \times \text { Wmagi }_{2 \mathrm{Dcg}}=\text { Cmagi } \times \mathrm{Cg} \times \text { Wmagi }_{2 \mathrm{D}}, \quad \boldsymbol{i}=1,2 \\
\text { Celi } \times \text { Weli }_{2 \mathrm{Dcg}}=\text { Celi } \times \mathrm{Cg} \times \text { Weli }_{2 \mathrm{D}}, \quad \boldsymbol{i}=1,2,3
\end{gathered}
$$

Another optimization process using 2D FEA identification procedures with these corrected energy values is then initiated. The correction factors are initialized to 1 for the first intermediate optimization step. After each intermediate optimization step, a 3D FEA simulation is performed. 


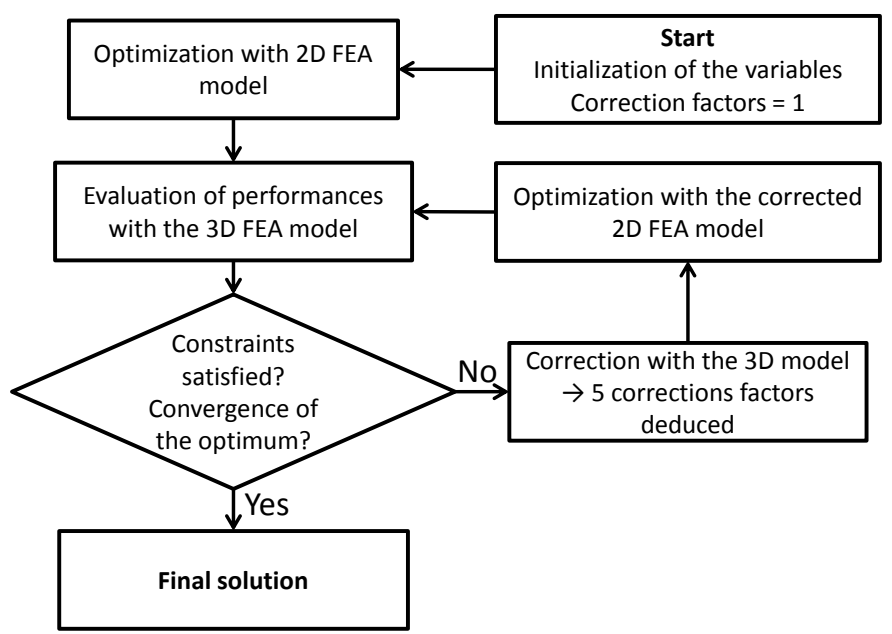

Figure 6: Flowchart of the hybrid design optimization method using a 3D FEA correction mechanism.

The correction factors are then computed. The final optimal solution is obtained when both set of parameters are identical.

\section{HYBRID DESIGN OPTIMIZATION EXAMPLE}

The hybrid optimization methodology has been applied to the design of the monolithic pulse transformer for the CLIC klystron modulator with the specifications listed on Table 1. The objective function to minimize was the transformer volume. Three intermediate optimization steps are sufficient to minimize the 2D FEA model errors and to validate the final optimal solution. The main transformer dimensions and the output voltage pulse settling time are listed (in Bold) in Table 3. The optimal result of the basic optimization methodology using 2D FEA identification procedures with the geometrical correction factor $\mathrm{C}_{\mathrm{g}}$ and no $3 \mathrm{D}$ FEA correction is also presented and normalized to the hybrid optimization solution. The output voltage pulse rise time and settling time obtained with the basic optimization methodology using 2D FEA and the hybrid design optimization methodology are presented on Fig.7.

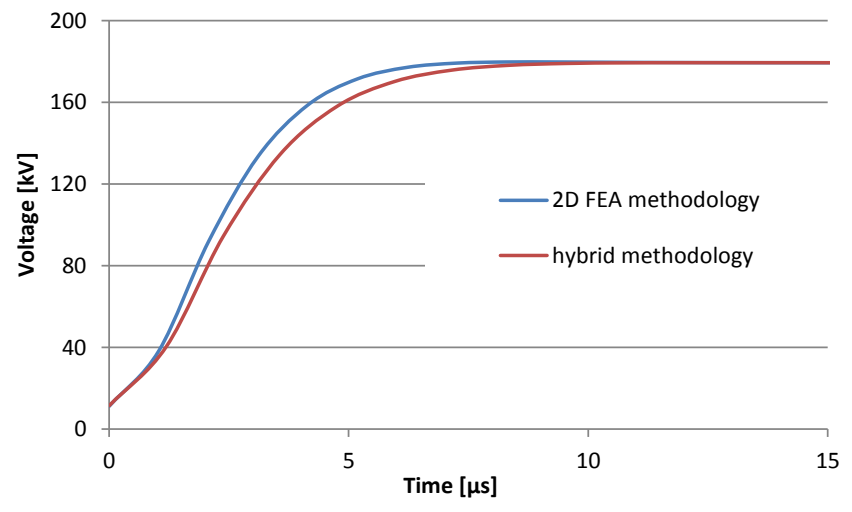

Figure 7: Output voltage pulse rise time and settling time obtained with the basic optimization methodology using 2D FEA and the hybrid design methodology

\section{CONCLUSION}

This study shows that it is possible to compensate the influence of the two-dimensional finite element modelling errors due to the contribution of the transformer end-winding region in the third dimension with a limited number of time consuming 3D FEA simulations by using a hybrid optimization methodology. The overall convergence of the process is very fast and the 3D FEA software always validates the optimal solution. The convergence of this method is verified in the case of the optimal design of a monolithic high voltage pulse transformer for the CLIC klystron modulator.

\section{REFERENCES}

[1] S. Candolfi, P. Viarouge, D. Aguglia, J. Cros, "Finite element based optimal design approach for high voltage pulse transformers", Pulsed Power Conference (PPC), 2013 19th IEEE, vol., no., pp.1,6, 16-21 June 2013

[2] P. Viarouge, D. Aguglia, C. A. Martins, J. Cros, "Modeling and dimensioning of High Voltage pulse transformers for klystron modulators", Electrical Machines (ICEM), 2012 XXth International Conference on, vol., no., pp.2332,2338, 2-5 Sept. 2012

[3] L.S. Lasdon, A.D. Waren, A. Jain and M. Ratner, "Design and testing of a generalized reduced gradient code for nonlinear programming", $A C M$ Transaction on Matheatical Software, Vol. 4, No.1, pp.34-49.

[4] G.N. Glasoe, J.V.L, Pulse Generators, New York: Dover Publications, Inc., 1965

Table 1: Optimization results with basic 2D FEA optimization and hybrid optimization methods for CLIC specifications.

\begin{tabular}{|c|c|c|c|c|c|}
\hline Optimization methodology & $\begin{array}{c}\text { Transformer } \\
\text { Volume }\end{array}$ & $\begin{array}{l}\text { Settling time 3D } \\
\text { FEA model [ } \mu \mathrm{s}]\end{array}$ & Core width & $\begin{array}{c}\text { Coil height } \\
{[\%]}\end{array}$ & $\begin{array}{c}\text { Number of turns } \\
{[\%]}\end{array}$ \\
\hline Basic 2D FEA optimization & $96 \%$ & $9.6 \mu \mathrm{s}$ & $93 \%$ & $92 \%$ & $97 \%$ \\
\hline Hybrid optimization & $\begin{array}{c}100 \% \\
0.069 \mathrm{~m}^{3}\end{array}$ & $8.0 \mu \mathrm{s}$ & $\begin{array}{c}\mathbf{1 0 0 \%} \\
\mathrm{e}_{\mathrm{c}}=0.094 \mathrm{~m}\end{array}$ & $\begin{array}{c}\mathbf{1 0 0 \%} \\
\mathrm{b}_{\mathrm{b}}=0.453 \mathrm{~m}\end{array}$ & $\begin{array}{l}\mathbf{1 0 0 \%} \\
\mathrm{n}_{1}=36\end{array}$ \\
\hline
\end{tabular}

